\section{OPEN ACCESS}

Edited by: Hikaru Hori,

University of Occupational and Environmental Health Japan, Japan

Reviewed by: Miao Qu,

Xuanwu Hospital, Capital Medical University, China

*Correspondence: Bangshan Liu bangshan.liu@csu.edu.cn

Lingjiang L 11i2920@163.com

${ }^{+}$These authors have contributed equally to this work

Specialty section:

This article was submitted to Mood and Anxiety Disorders, a section of the journal Frontiers in Psychiatry

Received: 11 March 2020 Accepted: 26 August 2020 Published: 16 September 2020

Citation:

Qin X, Sun J, Wang M, LuX, Dong Q, Zhang L, Liu J, Ju Y, Wan P, Guo H, Zhao F, Zhang Y, Liu B and Li L (2020)

Corrigendum: Gender Differences in Dysfunctional Attitudes in Major Depressive Disorder.

Front. Psychiatry 11:541955. doi: 10.3389/fpsyt.2020.541955

\title{
Corrigendum: Gender Differences in Dysfunctional Attitudes in Major Depressive Disorder
}

\author{
Xuemei Qin ${ }^{1,2 \dagger}$, Jinrong Sun ${ }^{1,2,3 \dagger}$, Mi Wang ${ }^{1,2}$, Xiaowen Lu ${ }^{1,2}$, Qiangli Dong ${ }^{1,2}$, \\ Liang Zhang ${ }^{1,2}$, Jin Liu ${ }^{1,2}$, Yumeng Ju ${ }^{1,2}$, Ping Wan ${ }^{4}$, Hua Guo ${ }^{4}$, Futao Zhao ${ }^{4}$, \\ Yan Zhang ${ }^{1,2}$, Bangshan $\mathrm{Liu}^{1,2 *}$ and Lingjiang $\mathrm{Li}^{1,2^{*}}$ \\ ${ }^{1}$ Department of Psychiatry, The Second Xiangya Hospital, Central South University, Changsha, China, ${ }^{2}$ Mental Health \\ Institute of Central South University, China National Clinical Research Center on Mental Disorders (Xiangya), China National \\ Technology Institute on Mental Disorders, Hunan Technology Institute of Psychiatry, Hunan Key Laboratory of Psychiatry and \\ Mental Health, Changsha, China, ${ }^{3}$ Affiliated WuTaiShan Hospital of Medical College of Yangzhou University, Yangzhou \\ Mental Health Centre, Yangzhou, China, ${ }^{4}$ Department of Psychiatry, Zhumadian Psychiatric Hospital, Zhumadian, China
}

Keywords: major depressive disorder, dysfunctional attitudes, gender differences, seeking applause, dependence, self-determination attitude, gender-specific interventions

\section{A Corrigendum on}

Gender Differences in Dysfunctional Attitudes in Major Depressive Disorder by: Qin X, Sun J, Wang M, Lu X, Dong Q, Zhang L, Liu J, Ju Y, Wan P, Guo H, Zhao F, Zhang Y, Liu B and Li L. (2020). Front. Psychiatry 11:86. doi: 10.3389/fpsyt.2020.00086

In the original article, there was a mistake in Table $\mathbf{2}$ as published. A $P$-value was missing in Table $\mathbf{2}$, on the row "Compulsion". The corrected Table 2 appears below. Meanwhile, the full name showed as "14-item Hamilton rating scale for depression" of the $\mathrm{HAMA}_{14}$ was wrong in the title of Table 4. The corrected title of Table 4 is as following: Multiple linear regression analyses for assessing effects of age, gender, education, BMI, smoking history, 24-item Hamilton rating scale for depression $\left(\mathrm{HAMD}_{24}\right)$, and 14 -item Hamilton anxiety rating scale $\left(\mathrm{HAMA}_{14}\right)$ predicting dysfunctional attitudes in major depressive disorder (MDD) patients.

We apologize for these errors and these do not change the scientific conclusions of the article in any way. The original article has been updated.

Copyright $\odot 2020$ Qin, Sun, Wang, Lu, Dong, Zhang, Liu, Ju, Wan, Guo, Zhao, Zhang, Liu and Li. This is an open-access article distributed under the terms of the Creative Commons Attribution License (CC BY). The use, distribution or reproduction in other forums is permitted, provided the original author(s) and the copyright owner(s) are credited and that the original publication in this journal is cited, in accordance with accepted academic practice. No use, distribution or reproduction is permitted which does not comply with these terms. 
TABLE 2 | Analysis of covariance (ANCOVA) of Chinese version of the dysfunctional attitude scale - form A (C-DAS-A) total and factor scores of major depressive disorder (MDD) and healthy control (HC) groups.

\begin{tabular}{|c|c|c|c|c|c|}
\hline \multirow[t]{2}{*}{ Item } & \multicolumn{2}{|c|}{ MDD } & \multicolumn{2}{|c|}{$\mathrm{HC}$} & \multirow[t]{2}{*}{$P$} \\
\hline & $\begin{array}{c}\text { Male } \\
(n=75)\end{array}$ & $\begin{array}{l}\text { Female } \\
(n=97)\end{array}$ & $\begin{array}{c}\text { Male } \\
(n=74)\end{array}$ & $\begin{array}{l}\text { Female } \\
(n=85)\end{array}$ & \\
\hline Total score & $150.17 \pm 25.98$ & $160.05 \pm 28.98$ & $126.92 \pm 29.94$ & $123.73 \pm 22.30$ & $<.001$ \\
\hline \multicolumn{6}{|l|}{ Factor scores } \\
\hline Vulnerability & $17.25 \pm 4.42$ & $18.72 \pm 4.67$ & $14.68 \pm 4.95$ & $14.81 \pm 4.13$ & $<.001$ \\
\hline Attraction and repulsion & $18.12 \pm 5.04$ & $18.53 \pm 6.25$ & $12.77 \pm 5.26$ & $12.93 \pm 4.76$ & $<.001$ \\
\hline Perfectionism & $18.21 \pm 5.29$ & $19.19 \pm 5.94$ & $15.15 \pm 5.96$ & $14.64 \pm 4.06$ & $<.001$ \\
\hline Compulsion & $18.28 \pm 4.50$ & $19.55 \pm 4.62$ & $16.15 \pm 4.30$ & $16.34 \pm 3.71$ & $<.001$ \\
\hline Seeking applause & $18.45 \pm 5.16$ & $20.40 \pm 5.47$ & $16.74 \pm 8.41$ & $15.59 \pm 4.91$ & $<.001$ \\
\hline Dependence & $18.67 \pm 4.00$ & $20.36 \pm 5.23$ & $15.78 \pm 5.09$ & $14.86 \pm 4.15$ & $<.001$ \\
\hline Self-determination attitude & $21.07 \pm 5.95$ & $23.03 \pm 5.28$ & $18.49 \pm 5.53$ & $17.24 \pm 4.62$ & $<.001$ \\
\hline Cognition philosophy & $20.12 \pm 5.08$ & $20.28 \pm 5.62$ & $17.16 \pm 5.37$ & $17.33 \pm 4.73$ & $<.001$ \\
\hline
\end{tabular}

Data are presented as mean $\pm S D$; Bold values indicate statistical significance; $P$ showed the difference in the C-DAS-A total and factor scores between MDD and HC groups; ANCOVA, analysis of covariance; C-DAS-A, Chinese version of the dysfunctional attitude scale - form A; MDD, major depressive disorder; HC, healthy control. 